\title{
ASSISTING FORCE FEEDBACK FUNCTION FOR HAND-HELD REMOTE CONTROL OF EXCAVATOR
}

\author{
Jarno UUSISALO, Otso KARHU and Kalevi HUHTALA \\ Department of Intelligent Hydraulics and Automation \\ Tampere University of Technology \\ P.O.Box 589, 33101 Tampere, Finland \\ (E-mail: jarno.uusisalo@tut.fi)
}

\begin{abstract}
Remote control of hydraulic mobile machines is often used because of safety issues. In addition to safety, remote control can be used to improve working efficiency and usability of the machine. A prototype of a hand-held remote control is designed to be used as a user interface of a mobile machine with an excavator while the machine is controlled remotely over short-range.

Since the remote control is designed to be used over short-range it provides congruent visual and voice feedback with the ordinary onboard user interface. In order to improve the feel of control an assisting force feedback function is implemented. The load of the machine is measured with a pressure transmitter. When the load tends to certain level information is provided to the operator. The idea is to inform the operator about the high load and possible power limitations, not to provide proportional force feedback.

Implementation of the system is introduced in this paper. The system is tested under real circumstances by using the excavator. Behaviour of the system during an excavation cycle is represented.
\end{abstract}

\section{KEY WORDS}

Remote control, Force feedback, Mobile machine, Excavator

\section{NOMENCLATURE}

$C A N$ : Controller Area Network

$C R C$ : Cyclic Redundancy Check

$D S P$ : Digital Signal Processor

FET : Field-Effect Transistor

$I / O \quad$ : Input/Output

$L C D$ : Liquid Crystal Display

$L E D \quad$ : Light Emitting Diode

$L S \quad$ : Load-Sensing

$R F \quad: \quad$ Radio Frequency

\section{INTRODUCTION}

Hydraulic mobile machines often work in dangerous or uncomfortable conditions. Protecting the operator of the machine against the environment may be difficult or expensive. For instance, damping the vibrations of the cab may increase the costs substantially. In some cases, using short-range remote control of the machine is an easier, better, and more cost effective way to carry out the task. Moreover, in some cases controlling the machine is more effortless for the operator when one can have a different view of the situation, not only the 
view from the cabin. [1]

In short-range remote control feedback is based on visual perception. Since expensive cameras are not needed short-range remote control is cost effective to be implemented and it can therefore be used also as an accessory feature with low cost machines. [2]

Several commercial remote controls for hydraulic mobile machines can be found on the market nowadays. In general terms the appearance of those commercial remote controls is quite similar. The enclosure of the remote control is relatively large and it is often supported with a strap behind the neck. The user interface is custom-made. Number of joysticks (usually no more than two), buttons, and switches depend on the application. Feedback for the operator is provided with LEDs and in some cases with an LCD panel. Wireless connection is implemented by exploiting frequency bands which are exempt from licensing.

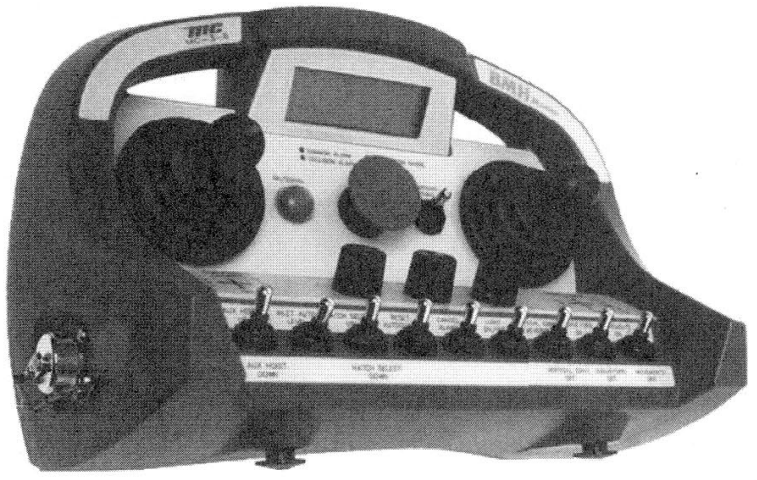

Figure 1 MC-3-6 remote control by Cavotec Micro-control [3]

Lack of force feedback is often considered to be the biggest disadvantage of remote control. It is often said that controllability of the machine is getting worse while using remote control since the operator can not feel the load of the machine. However, if the traditional onboard user interface of the hydraulic mobile machine is considered force feedback joysticks are not utilized in the cab. The joysticks are insensitive to the load of the machine. Feedback of the load is actually based on secondary feelings such as the vibrations of the machine and engine sound. On the grounds of these secondary perceptions a human being automatically visualizes the load level. If similar feelings can be provided while using remote control usability and controllability may be improved. Commercial solutions do not provide this feature.

A prototype of a hand-held remote control is developed at the Department of Intelligent Hydraulics and Automation at Tampere University of Technology. The hand-held remote control provides assisting force feedback information for the operator. This paper introduces the idea and implementation of a cost effective assisting force feedback function which is based on eccentric electric motors.

\section{REMOTELY CONTROLLED HYDRAULIC MOBILE MACHINE WITH EXCAVATOR}

A prototype of the remotely controlled hydraulic mobile machine (see Fig. 2) which is used as a test platform while testing the hand-held remote control is based on the commercial machine Avant 320+ manufactured by Avant Tecno Oy [4]. The body of the machine is original. Instead, hydraulics and electronics have been re-designed in order to make remote control of the machine possible.

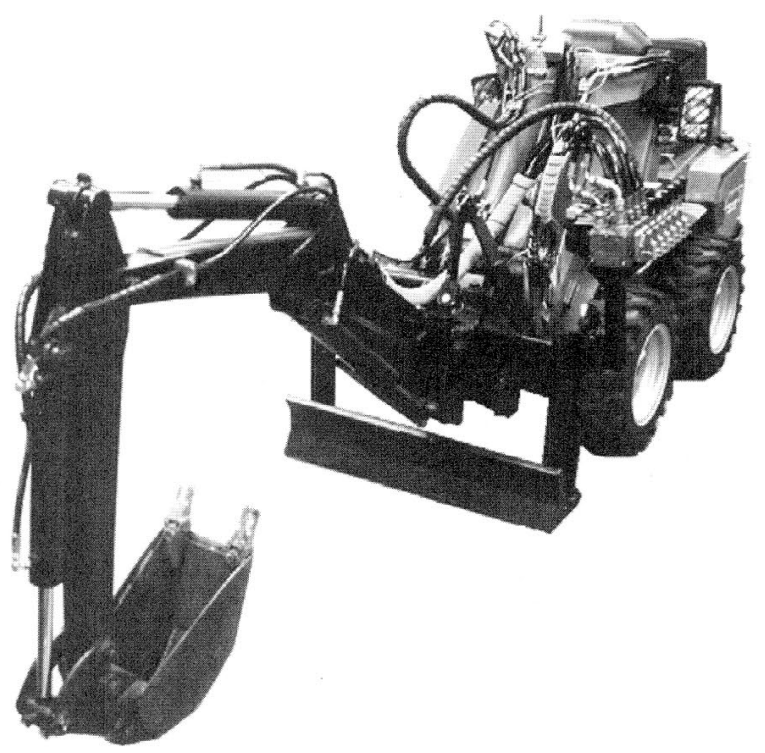

Figure 2 The prototype of the remotely controlled hydraulic mobile machine which is used as a test platform [5]

Various attachments such as different kinds of buckets and brooms can be attached to the basic machine. In this paper the excavator is studied. [4]

\section{Hydraulics of the machine}

The power transmission, telescope boom, and bucket of the modified machine are controlled with one valve block. The valve block consists of six electronically actuated proportional spool valves. One of these proportional valves of the block is used for external hydraulics, in this case for the excavator. The proportional valve block includes internal LS line which shows the highest load pressure of the system [6]. The LS pressure is measured by means of a pressure transmitter [7]. The hydraulic diagram of the machine without the excavator is shown in Fig 3. 


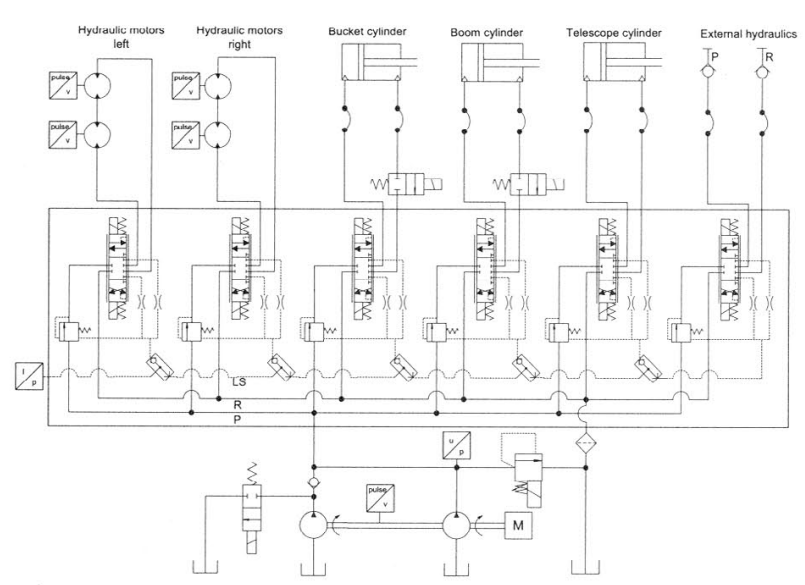

Figure 3 The hydraulic diagram of the machine without the excavator

Similar proportional valve block controls four cylinders of the excavator. The valve is attached to the body of the excavator. Also this valve includes LS line. The pressure and return lines are connected to the external hydraulics valve in the valve block of the basic machine (see Fig. 3 ). The port is opened when the excavator is used.

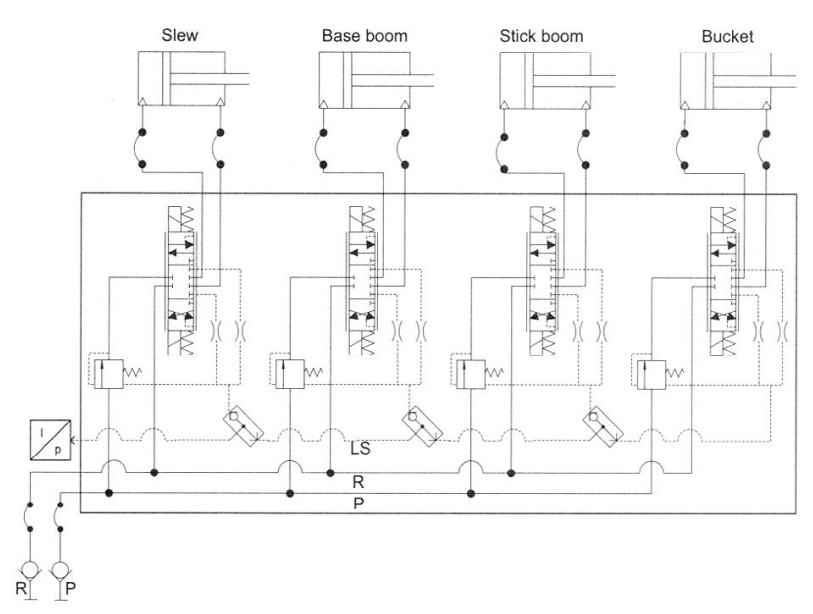

Figure 4 The hydraulic diagram of the excavator

\section{Electronics of the machine}

Electronics of the machine is distributed and communication between the modules is carried out via CAN bus. The display module DM586 is the main controller of the machine. It takes care of all high level control tasks of the machine and communicates with the remote control via serial port. Sensor values such as the LS pressure of the machine are read by means of $\mathrm{I} / \mathrm{O}$ modules. $[1,8]$

The excavator is controlled with the excavator control unit [9]. The control unit measures the LS pressure of the excavator with the interval of $1 \mathrm{~ms}$. The pressure is filtered with a moving average filter. The filtered value is sent to the main controller (DM586) every $10 \mathrm{~ms}$ via CAN bus. The algorithm of the moving average filter is represented in Eq. 1. [10]

$$
\text { Average }_{n}=\text { Average }_{n-1}+\frac{\text { Input value }- \text { Average }_{n-1}}{\text { Filter constant }}
$$

\section{HAND-HELD REMOTE CONTROL}

The enclosure of the prototype of the hand-held remote control is from a cordless game controller for Playstation 2, manufactured by Logitech [11]. Instead, electronics and software are totally re-designed and custom-made for this application. Two joysticks of the remote control are used for controlling different actuators depending on the functional mode. Three LEDs provide state information about some important states of the system for the operator. $[1,2]$

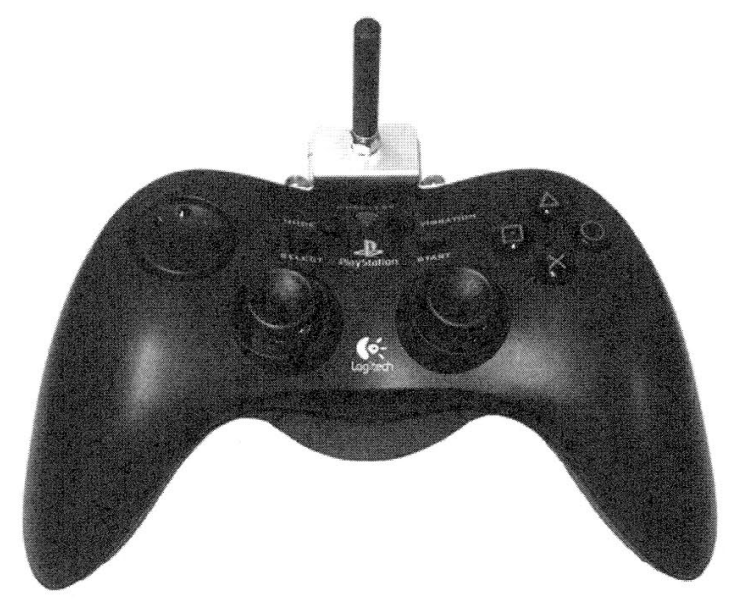

Figure 5 The prototype of the hand-held remote control

The effect of remote control on working efficiency and usability of the excavator were determined by means of an interview study. 18 testees executed same task with three different user interfaces. Remote control improved both the working efficiency and the usability. In test case, however, processed soil was homogenous and on that account conclusions from actual effect of force feedback can not be drawn. [1]

Data transmission protocol

The wireless connection between the remote control and the machine is implemented by using commercial radio modems. The half duplex data transmission and the baud rate of $38400 \mathrm{bps}$ are used. The data transmission protocol is designed for this application. Nine bytes are sent in every data packet and every byte consists of start bit, eight data bits, and stop bit. New control data is sent every $50 \mathrm{~ms}$. [12]

Contents of the sent and received data packets are 
represented in tables 1 and 2 . In table 1 the start byte is a constant value which expresses the beginning of the data packet. It also separates similar remote controls from each other if several machines are controlled at the same worksite. The index number byte includes running four-bit number. On the grounds of the index number the receiver can make sure that data is updated. The $\mathrm{CRC}$ byte is used for checking if the data is corrupted during the transmission.

Table 1 The sent data packet to the machine

\begin{tabular}{|c|l|}
\hline Byte no. & Data \\
\hline 1 & Start byte \\
\hline 2 & Gas / Base boom of excavator \\
\hline 3 & Steering / Bucket of excavator \\
\hline 4 & Boom / Stick boom of excavator \\
\hline 5 & Bucket / Slew of excavator \\
\hline 6 & External hydraulics \\
\hline 7 & Button states \\
\hline 8 & Index number and button states \\
\hline 9 & CRC \\
\hline
\end{tabular}

Once the main controller of the machine receives correct data packet, it sends the feedback packet to the remote control. The feedback packet includes only one data byte and the CRC byte.

Table 2 The received data packet from the machine

\begin{tabular}{|c|l|}
\hline Byte no. & Data \\
\hline 1 & Feedback data \\
\hline 2 & CRC \\
\hline
\end{tabular}

\section{ASSISTING FORCE FEEDBACK SYSTEM}

Operator's perceptions of the load level of the machine are mostly based on engine sound and the vibrations of the cab. While using short-range remote control the operator is always close to the machine since the machine has to be seen. On that account, the operator will always hear engine sound. Therefore, the only feedback that the operator misses is the sense of vibrations.

Usually the operator is not interested in the load level until it is about to reach the maximum force capacity of the machine. When the maximum capacity is reached the operator either releases or changes the control. Thus, proportional force feedback is not necessary required.

The idea of the assisting force feedback function of the hand-held remote control is to provide for the operator information when the load of the machine increases significantly, close to maximum. Quality force feedback joysticks can not be integrated to a small device such as the hand-held remote control. In this case, the force feedback information is produced by vibrating the device instead of using force feedback joysticks. The vibration is generated by means of two eccentric electric motors (see Fig. 6). Since the motors are of a different size four various strength of vibration can be implemented.

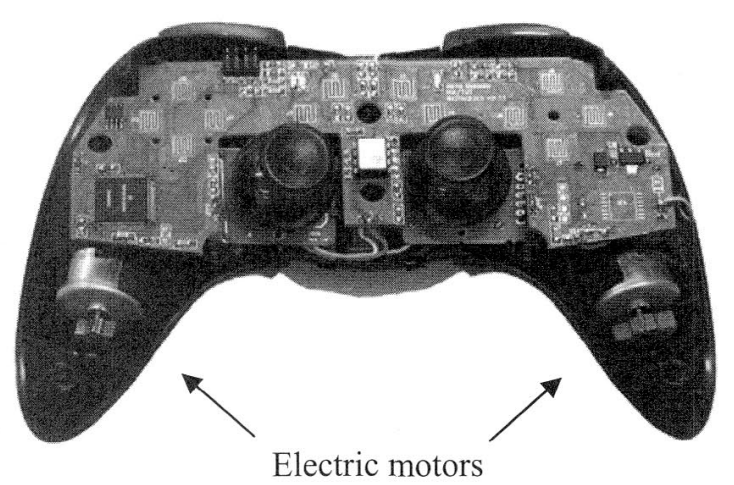

Figure 6 The remote control without the cover. Eccentric clectric motors are mounted to the handles

The main controller of the machine (DM586) filters the highest LS pressure of the whole system (LS pressure of the basic machine or LS pressure of the excavator) during the past $50 \mathrm{~ms}$ utilizing the moving average filter (see Eq. 1). $50 \mathrm{~ms}$ window is used since new control data from the hand-held remote control is received every $50 \mathrm{~ms}$. Depending on the filtered LS pressure one of four load levels is selected. The load levels can be adjusted on-line by tuning parameters in the main controller of the machine.

Information about the current load level is transferred from the machine to the remote control with a two-bit value which is included to the feedback data byte (see Table 2). On the grounds of feedback the eccentric electric motors are controlled.

\section{Control of electric motors}

Control of the electric motors is on/off type. Since DSP56F803 which is used as a controller of the remote control can not drive enough current SMART FETs are utilized as amplifier stages. [13, 14]

A disadvantage of the electric motors is electromagnetic interferences. Especially in this case when the motors are close to the processor and RF signals are used interferences have to be taken into account. Passive filtering is utilized in this application. The schematic of the amplifier stage and filtering is shown in Fig. 7. 


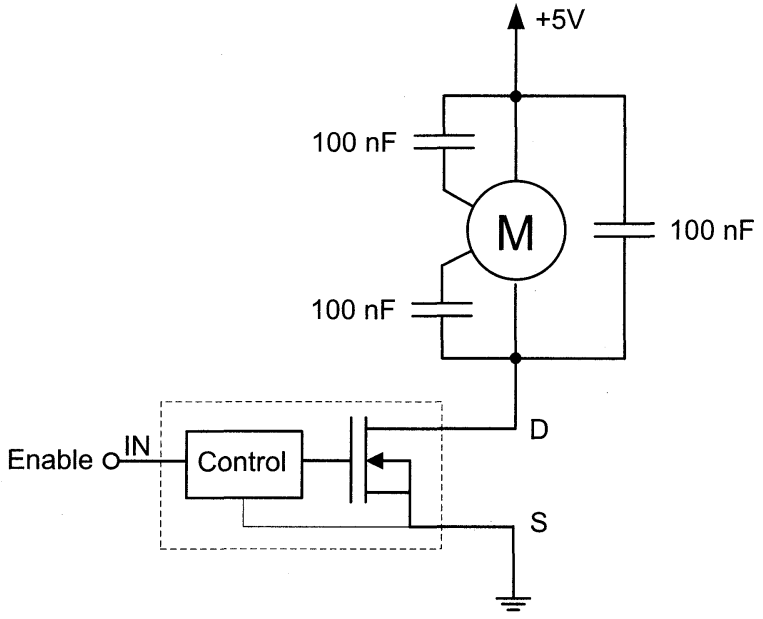

Figure 7 The schematic of the filter and amplifier stage of the electric motors.

\section{BEHAVIOUR OF THE SYSTEM DURING EXCAVATION CYCLE}

The system was tested by controlling the excavator remotely. Figs. 8-10 show the behaviour of the system during one excavation cycle. In the test run the bucket of the excavator was filled once by moving all joints. After that the excavator was slewed aside and the bucket was emptied. Finally the excavator was returned back for the next cycle. During the test run the load increased so high that the maximum force capacity of the machine was exceeded. The control values are shown in Fig. 8 and the filtered LS pressure in Fig. 10.

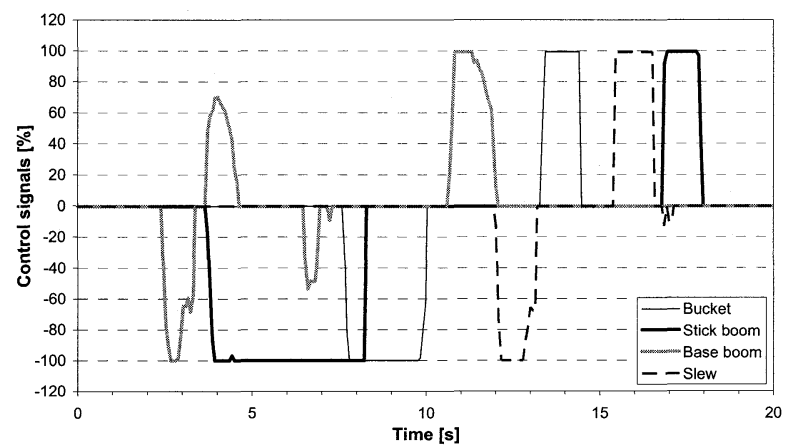

Figure 8 The control values of the excavator during the excavation cycle

The orientation of the excavator was measured by means of a potentiometer and three inclinometers. The potentiometer was utilized for measuring the position of the slew cylinder [5]. The inclinometers (with modified software compared to reference) were attached to the base boom, stick boom, and bucket of the excavator [15]. Approximations of the joint angles were calculated by subtracting the angle values from each other. The slew angle and the relative joint angles are illustrated in Fig. 9. Some offset have been added to the joint angles to fit curves in one figure. High frequency oscillation and peaks can be noticed in Fig. 9. This oscillation is due to characteristic of the inclinometers utilized in the measurements. In this case peaks and oscillation can be ignored.

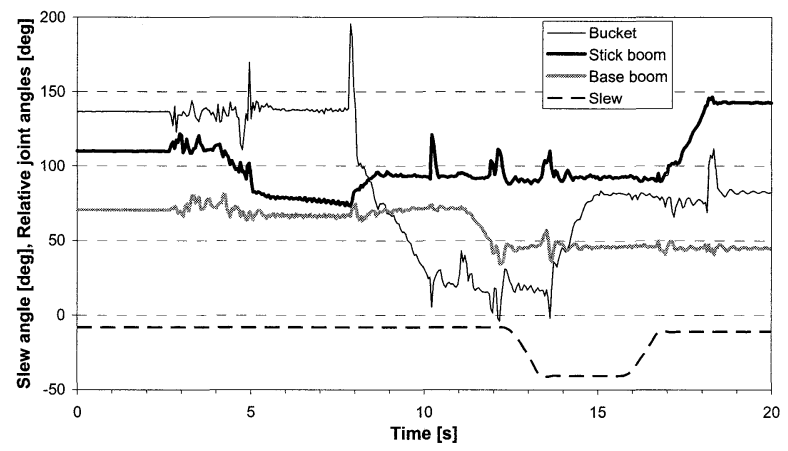

Figure 9 Variation of the angles during the test run. The joint angles are relative values which show the approximation of variation

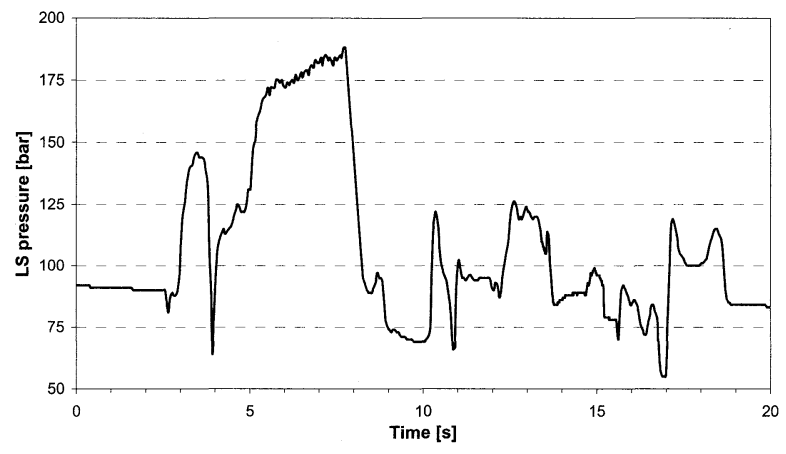

Figure 10 The filtered LS pressure of the excavator

The idea of the assisting force feedback system is to inform the operator when the load tends to the maximum force capacity of the machine. Thus, the pressure behaviour close the maximum pressure is important. In this case the maximum pressure of the system is about 180 bar.

Let us consider more carefully the period from 4 to 9 seconds in Figs. 8-10. After the control of the stick boom is activated (at $4 \mathrm{~s}$ ), the joint angle of the stick boom starts to change. At the same time the LS pressure increases. During the period from 5 to 7.8 seconds the joint angles of the excavator do not vary significantly even though the stick boom is controlled with the maximum control value. After 5 seconds the LS pressure increases rapidly to 175 bar. The LS pressure 
remains high until the bucket is controlled at 7.8 seconds. The change in the angle of the bucket decreases the load of the excavator and the LS pressure drops rapidly. In other words, between 5 and 7.8 seconds nothing moves significantly regardless of the controls since the machine does not have enough power to execute the controls. At this time the LS pressure remains almost constant. At other times the machine is able to execute the controls and the LS pressure varies without reaching the maximum value.

If the pressure level which enables force feedback is adjusted to 170 bar the system starts to vibrate the remote control at 5.5 seconds. On the ground of the vibration the operator knows that the maximum force capacity of the machine is achieved. The vibration stops immediately when the operator changes the controls so that the load decreases (in this case controls the bucket).

\section{CONCLUSIONS}

Lack of feedback is often considered to be one of the biggest disadvantages of remote control. While using short-range remote control the operator gets good visual feedback including stereoscopic vision. An advantage compared to the traditional onboard user interface is that the angle of view can be changed according to need. Short-range remote control also offers sound feedback. In addition to visual and sound feedbacks the onboard user interface provides force feedback at some level. In real terms the operator composes so called force feedback of the vibrations of the machine and engine sound.

In this paper the idea of the assisting force feedback system for the hand-held remote control is introduced. The load of the machine is measured by means of the LS pressure of the system. The remote control includes two eccentric electric motors which are utilized for vibrating the remote control when the load level of the machine exceeds certain level. Four different strengths of vibrations can be produced.

The system was tested by means of the hydraulic mobile machine with the excavator attachment. Behaviour of the system during one excavation cycle is represented. The goal was to detect the situation when the machine can not execute the control task because of the limited force capacity and inform the operator about the lack of force. According to measurements this phenomenon can be discovered by measuring the LS pressure and the system designed works.

\section{FUTURE WORK}

In future more tests have to be carried out to find out how the system works in different conditions. Also a usability test has to be arranged to discover whether the system improves usability of the machine.

\section{REFERENCES}

1. Uusisalo, J. R. A., Karhu, O. I., and Huhtala, K. J., A., Hand-Held Remote Control as a User Interface for a Hydraulic Mobile Machine with an Excavator, Proceedings of the $51^{\text {st }}$ National Conference on Fluid Power, Las Vegas, NV, USA, 2008.

2. Uusisalo, J. R. A., Vilenius, J. M., Vuohijoki, A. J., Hirvonen, S.-M., Karhu, O. I., and Huhtala, K. J., Portable Remote Control for Teleoperated Hydraulic Mobile Machine, Proceedings of the Tenth Scandinavian International Conference on Fluid Power, Vol. 3, Tampere, Finland, 2007, pp. 35-45.

3. Radio Remote Control Systems, Brochure, Lugano, Switzerland, 2007, Cavotec Micro-control AS.

4. Avant 300 series, 500 series, Brochure, Ylöjärvi, Finland, 2005, Avant Tecno Oy.

5. Karhu, O. I., Moya, J., Uusisalo, J. R. A., and Huhtala, K. J., Enabling Autonomous Functions on Hydraulic Excavator Attachment, Proceedings of the Tenth Scandinavian International Conference on Fluid Power, Vol. 2, Tampere, Finland, 2007, pp. 35-45.

6. PVG 32 Proportional Valves, Technical Information, Lincolnshire, IL, USA, 2006, Sauer-Danfoss Inc.

7. EXNA250.0A Pressure Transmitter, Data Sheet, Männedorf, Germany, 2006, Trafag AG.

8. Display Module DM586, Technical Data Sheet, Tampere, Finland, 2003, Axiomatic Technologies Oy.

9. Karhu, O. I., Vilenius, J. M., Uusisalo, J. R. A., Moya, J., and Huhtala, K. J., Intelligent Excavator for Hydraulic Mobile Machine, Proceedings of the $22^{\text {nd }}$ International Symposium on Automation and Robotics in Construction, Ferrara, Italy, 2005, 5 pp.

10. CANopen Quad Controller, User Manual UMAX020502, version 1.04, Mississauga, ON, Canada, 2006, Axiomatic Technologies Corp.

11. Logitech Cordless Action Controller for Sony Playstation 2. http://www.logitech.com. (Referred 7.12.2006)

12. Ultracom UC800 Radio Modem, Brochure, Kempele, Finland, 2004, Ultracom Oy.

13. IPS021 SMART POWER MOSFET, Data Sheet, El Segundo, CA, USA, 2001, International Rectifier.

14. DSP56F803, Data Sheet, Austin, TX, 2005, Freescale Semiconductor Inc.

15. Honkakorpi, J., CAN-bus based embedded inclinometer, Master of Science thesis, Tampere, Finland, 2007, 47 p. (in Finnish) 